\title{
Colony size-frequency distributions of scleractinian coral populations: spatial and interspecific variation
}

\author{
E.H.Meesters ${ }^{1, *}$, M.Hilterman ${ }^{2}$, E. Kardinaal ${ }^{2}$, M.Keetman ${ }^{2}$, M. de Vries ${ }^{2}$, R.P.M.Bak ${ }^{1,2}$ \\ ${ }^{1}$ Netherlands Institute for Sea Research (NIOZ), PO Box 59, 1790 AB Den Burg, Texel, The Netherlands \\ ${ }^{2}$ Institute for Systematics and Population Biology, University of Amsterdam, PO Box 94766, 1090GT Amsterdam, The Netherlands
}

\begin{abstract}
Colony size is an important characteristic for clonal modular organisms such as corals because life-history processes, e.g. reproduction and mortality, are strongly related to size. These processes are affected by the environment, and size-frequency distributions of coral populations provide information on the responses of populations to environmental conditions. We hypothesised that the size-frequency structure of coral populations in degraded environments would differ from those in a more pristine environment. We used log-transformed colony-size data of 13 coral species from the fringing reefs of Curaçao, Netherlands Antilles. Data were collected at 4 sites, representing 2 environments: a heavily urbanised coastal area with degraded reefs, and an upstream control area. Population structure was dependent on species and site. Size-frequency distributions of the same species from different sites were twice as similar as distributions of different species, indicating the strong effects of various life-history traits among species. Site effects were indicated by significant differences between distributions of 11 species at 4 sites. Mean colony size varied up to an order of magnitude between species, and much less between sites; however, in 10 species mean colony size was also significantly different among the 4 sites. The pattern of the differences was not consistent among species, indicating that mean colony size in degraded sites was higher for some species and lower for others. Parameters describing the shape of the population appeared to reflect a general response to reef condition. In the degraded area, frequency distributions tended to show increased negative skewness, occasionally extreme positive kurtosis, and smaller standard deviations: 11 populations were generally more negatively skewed, with the bulk of the population concentrated in the larger size classes; kurtosis was on average higher and extremely peaked; and standard deviations indicated that colony size varied less. This evidence suggests lower recruitment and higher partial mortality in larger colonies in this area. Lower recruitment decreased the influx into the smaller size classes of the populations, and higher partial colony-mortality decreased the proportion of colonies in the higher size classes while simultaneously increasing the proportion of colonies in the medium-sized classes. Species that attained large sizes (indicative of great age) appeared to have size-frequency distributions skewed to the left, while small species were more skewed to the right. The data indicate a general dichotomy in coral lifehistory strategies with respect to colony size, with small species generally having a shorter lifespan and reproduction being relatively frequent and successful. Thus, new input into smaller size classes occurs continuously. Species that attain large sizes live longer and are less dependent on frequent recruitment, and consequently populations tend to become 'impoverished' in small colonies, resulting in size-frequency distributions that are skewed to the left. Based on changes in population structure, this research indicates that some species, such as Colpophyllia natans and Diploria labyrinthiformis, are relatively sensitive to environmental conditions.
\end{abstract}

KEY WORDS: Coral reefs $\cdot$ Degradation $\cdot$ Monitoring $\cdot$ Health $\cdot$ Pollution $\cdot$ Size hierarchy $\cdot$ Population structure

Resale or republication not permitted without written consent of the publisher

\section{INTRODUCTION}

There is an urgent need to better understand the effects of human influence on coral populations, as

*E-mail: erikm@nioz.nl reefs appear to be globally deteriorating (Buddemeier 1993, Wilkinson 1993, Ginsburg \& Glynn 1994, Birkeland 1996). Population ecology provides important tools for understanding life-history processes and predicting population structure and development, but little attention has been paid to in situ changes in sessile 
populations (but see e.g. Hughes \& Jackson 1985, Fong \& Glynn 1998). Corals are slow-growing organisms characterised by high longevity. To observe the dynamics and understand the mechanisms of changes in coral populations, separate censuses over longer time scales are necessary (Hughes \& Jackson 1985, Babcock 1991, Bak \& Nieuwland 1995, Aronson \& Precht 1997).

Population demography is concerned with population structure and population dynamics. Differences between individuals, e.g. in age, affect reproduction, growth, mortality, and migration rates. This has led to the design of structured population models that keep track of these individual differences by using functions that relate life-history processes to certain categories (e.g. age classes) of the population (Leslie 1945). Population structure, the number of individuals per category, is the corollary of the individual sensitivities to life-history processes.

In terms of understanding population dynamics and the stage of development of a coral population, much of the information that is traditionally gathered in reef coral community surveys, such as coral cover, is of limited use. Ecologists tend to be very 'mean-minded' (Underwood 1997). Means and variances of data sets are routinely calculated, but parameters of the shape of frequency distributions as a measure of population structure are hardly ever mentioned, although these can provide useful information about ecological processes and their effects on populations. For example, the impact of environmental degradation on population structure will vary depending on the life-history process and level of the population that is affected. This lack of population-structure parameters in coral science may arise from the need for large data sets in such studies.

Hermatypic corals are clonal modular organisms and their life cycle is complicated by fragmentation, fission, fusion, and partial mortality (Bak 1975, Highsmith et al. 1980, Hughes \& Jackson 1980, 1985, Meesters et al. 1996, 1997). Individuals of similar size may differ greatly in age. Within the biology of clonal organisms, biotic and abiotic processes appear to be much more related to size than age (Connell 1973, Loya 1976b, Hughes \& Connell 1987, Szmant 1991, Soong 1993). Consequently, population structure is better described by size than by age. The shape of the distribution is the result of age- or size-specific rates of growth and survival, their variability, and seasonal and interannual variation in recruitment (Ebert et al. 1993). Coral colony-size distributions show characteristics similar to those of many plant populations. Most populations consist of many small individuals and relatively few large ones (Bythell et al. 1993, Bak \& Meesters 1998). Bak \& Meesters (1998) showed how logarithmic transformation of coral-size data produces a better view of population structure in scleractinian corals. Size distributions of transformed data have higher resolution and reflect more closely an approximate age distribution than distributions of non-transformed data. This is caused by underlying first-order processes such as juvenile survival (Gosselin \& Qian 1997), growth (Bak 1976), and adult mortality (Meesters et al. 1997). Environmental influences will change population structure, and this should be reflected in parameters of frequency distributions such as standard deviation, skewness and kurtosis. To be able to discuss effects of global change and predict its effects on coral populations, we must understand the responses of coral populations to environmental variation at intra- and interspecific levels (Bak \& Meesters 1997, 1998). Studying present-day population structures at different locations may reveal long-term consequences of small changes in environmentally sensitive life-history processes.

We studied how the size structure of coral populations varies in different environments and looked for differences among species. Here, we present data on size-frequency distributions of reef corals from 2 areas differing in degree of anthropogenic disturbance. We hypothesised that reefs under the influence of environmental degradation would show discernible patterns in coral population structure caused by reduced recruitment and/or increased partial and whole colony mortality. These patterns should be expressed in the parameters of the distributions.

\section{MATERIAL AND METHODS}

Colonies of 13 coral species (Table 1) were measured (using SCUBA) along $1 \mathrm{~m}$-wide belt transects at a depth of 6 to $10 \mathrm{~m}$ from February to June 1996. In each of 2 environmentally different areas, we haphazardly selected 2 sites. One area was directly offshore from the main industrial and urban centre of Curaçao with sites at Avila and Marie Pompoen. In this area, reefs are degraded, with generally lower species diversity and lower living coral cover due to increased turbidity and eutrophication (see van Duyl 1985, Gast et al. 1999 for details). The control area, with sites at Seaquarium and Cornelisbay, is approximately $2 \mathrm{~km}$ upstream and, because the main current direction is invariably northwest, outside the influence of the city of Willemstad (Fig. 1).

A colony was defined as any autonomous coral skeleton with living tissue. Coral divided by partial mortality into separate patches of living tissue, but morphologically still 1 entity, was considered a single colony. For each colony we measured maximum height, maximum diameter, diameter at right angles 
Table 1. Distribution parameters of logarithmically transformed size (surface area) data for 13 coral species at 4 sites (AV: Avila; MP: Marie Pompoen; SQ: Seaquarium; CB: Cornelisbay). $\mu$ : geometric mean size $\left(\mathrm{cm}^{2}\right)_{i} \mathrm{~g}_{1}$ : skewness; $\mathrm{g}_{2}$ : kurtosis; $95 \%$ : 95 th percentile; $\mathrm{p}_{\text {norm}}$ : probability that data are from normal distribution (Kolmogorov-Smirnov test using Lilliefors adjusted probability); $\mathrm{n}$ : total number of colonies measured

\begin{tabular}{|c|c|c|c|c|c|c|c|c|}
\hline Species & Site & $\mu$ & $g_{1}$ & $g_{2}$ & $95 \%$ & $\mathrm{SD}$ & $\mathrm{p}_{\text {norm }}$ & $\mathrm{n}$ \\
\hline \multirow[t]{4}{*}{ Agaricia agaricites } & $\mathrm{AV}$ & 109 & -0.321 & -0.992 & 2293 & 2.29 & 0.008 & 87 \\
\hline & MP & 72 & -0.258 & -0.831 & 1730 & 2.20 & 0.028 & 52 \\
\hline & $\mathrm{SQ}$ & 42 & 0.398 & -0.630 & 1653 & 2.09 & 0.000 & 313 \\
\hline & $\mathrm{CB}$ & 50 & -0.220 & -0.590 & 1497 & 2.17 & 0.164 & 171 \\
\hline \multirow[t]{4}{*}{ Agaricia humilis } & $\mathrm{AV}$ & 5 & -0.511 & -0.113 & 31 & 1.18 & 0.000 & 115 \\
\hline & MP & 8 & -0.339 & 0.529 & 55 & 1.11 & 0.126 & 116 \\
\hline & $\mathrm{SQ}$ & 9 & 0.038 & 0.490 & 72 & 1.30 & 0.000 & 238 \\
\hline & $\mathrm{CB}$ & 6 & -0.322 & -0.346 & 45 & 1.25 & 0.006 & 132 \\
\hline \multirow[t]{4}{*}{ Colpophyllia natans } & $\mathrm{AV}$ & 1346 & -1.684 & 3.302 & 10594 & 2.04 & 0.000 & 113 \\
\hline & MP & 426 & -0.285 & -0.819 & 10707 & 2.35 & 0.231 & 67 \\
\hline & $\mathrm{SQ}$ & 240 & 0.045 & -0.923 & 14644 & 2.67 & 0.012 & 109 \\
\hline & $\mathrm{CB}$ & 269 & -0.148 & -0.474 & 12497 & 2.45 & 0.741 & 104 \\
\hline \multirow[t]{4}{*}{ Dichocoenia stokesii } & $\mathrm{AV}$ & 477 & -0.930 & 1.201 & 3421 & 1.39 & 0.039 & 118 \\
\hline & MP & 605 & -1.243 & 3.086 & 2865 & 1.30 & 0.000 & 109 \\
\hline & $\mathrm{SQ}$ & 432 & -0.489 & 0.152 & 2816 & 1.22 & 0.588 & 27 \\
\hline & $\mathrm{CB}$ & 814 & -1.034 & 1.492 & 5110 & 1.49 & 0.334 & 20 \\
\hline \multirow[t]{4}{*}{ Diploria labyrinthiformis } & $\mathrm{AV}$ & 85 & -0.655 & 1.866 & 1384 & 1.85 & 0.282 & 37 \\
\hline & MP & 74 & -0.457 & -0.537 & 2843 & 2.49 & 0.018 & 87 \\
\hline & $\mathrm{SQ}$ & 266 & -0.427 & -0.438 & 7998 & 2.59 & 0.189 & 55 \\
\hline & $\mathrm{CB}$ & 50 & 0.277 & -0.321 & 4661 & 2.53 & 0.026 & 107 \\
\hline \multirow[t]{4}{*}{ Diploria strigosa } & $\mathrm{AV}$ & 150 & -0.821 & 0.019 & 3565 & 2.61 & 0.003 & 110 \\
\hline & MP & 94 & -0.603 & -0.385 & 1821 & 2.35 & 0.014 & 113 \\
\hline & $\mathrm{SQ}$ & 233 & -0.126 & -0.956 & 5821 & 2.24 & 0.060 & 116 \\
\hline & $\mathrm{CB}$ & 53 & 0.014 & -0.497 & 2248 & 2.21 & 0.401 & 57 \\
\hline \multirow[t]{4}{*}{ Eusmilia fastigiata } & $\mathrm{AV}$ & 239 & -0.571 & 0.733 & 4086 & 1.82 & 0.066 & 35 \\
\hline & MP & 103 & -0.205 & -0.196 & 441 & 1.68 & 0.556 & 13 \\
\hline & $\mathrm{SQ}$ & 113 & -0.958 & 1.263 & 1083 & 1.66 & 0.097 & 77 \\
\hline & $\mathrm{CB}$ & 72 & -0.867 & 0.035 & 835 & 1.96 & 0.005 & 72 \\
\hline \multirow[t]{4}{*}{ Meandrina meandrites } & $\mathrm{AV}$ & 166 & -0.392 & 0.031 & 2747 & 1.88 & 1.000 & 131 \\
\hline & MP & 53 & -0.139 & -0.218 & 1642 & 2.14 & 0.617 & 108 \\
\hline & $\mathrm{SQ}$ & 105 & -0.379 & 0.323 & 2001 & 1.94 & 0.070 & 103 \\
\hline & $\mathrm{CB}$ & 29 & -0.107 & 0.721 & 455 & 1.70 & 0.208 & 113 \\
\hline \multirow[t]{4}{*}{ Montastraea annularis } & $\mathrm{AV}$ & 1382 & -1.561 & 2.178 & 9371 & 1.80 & 0.000 & 104 \\
\hline & MP & 1062 & -0.692 & 0.029 & 8471 & 1.57 & 0.008 & 101 \\
\hline & $\mathrm{SQ}$ & 3062 & -0.875 & 0.447 & 33295 & 1.73 & 0.000 & 103 \\
\hline & $\mathrm{CB}$ & 1876 & -1.008 & 0.765 & 13155 & 1.62 & 0.000 & 117 \\
\hline \multirow[t]{4}{*}{ Montastraea cavernosa } & $\mathrm{AV}$ & 697 & -0.522 & 0.268 & 6817 & 1.53 & 0.129 & 118 \\
\hline & MP & 787 & -1.584 & 3.245 & 5527 & 1.79 & 0.000 & 106 \\
\hline & $\mathrm{SQ}$ & 769 & -0.545 & -0.412 & 9139 & 1.81 & 0.030 & 114 \\
\hline & $\mathrm{CB}$ & 823 & -1.304 & 1.865 & 7733 & 1.84 & 0.000 & 107 \\
\hline \multirow[t]{4}{*}{ Montastraea faveolata } & $\mathrm{AV}$ & 3093 & -0.774 & 0.854 & 22190 & 1.41 & 0.186 & 52 \\
\hline & MP & 2930 & -0.829 & 0.692 & 19641 & 1.37 & 0.007 & 73 \\
\hline & $\mathrm{SQ}$ & 3381 & -1.089 & 1.187 & 26463 & 1.81 & 0.065 & 68 \\
\hline & $\mathrm{CB}$ & 3022 & -1.212 & 0.765 & 25748 & 2.03 & 0.001 & 74 \\
\hline \multirow[t]{4}{*}{ Porites astreoides } & $\mathrm{AV}$ & 66 & -0.635 & 0.787 & 869 & 1.81 & 0.057 & 139 \\
\hline & MP & 40 & -0.770 & 0.304 & 505 & 1.96 & 0.008 & 119 \\
\hline & $\mathrm{SQ}$ & 58 & -0.625 & -0.118 & 646 & 1.80 & 0.001 & 116 \\
\hline & $\mathrm{CB}$ & 29 & -0.323 & -0.862 & 894 & 2.37 & 0.003 & 128 \\
\hline \multirow[t]{4}{*}{ Siderastrea siderea } & $\mathrm{AV}$ & 271 & -0.750 & -0.151 & 6857 & 2.64 & 0.000 & 128 \\
\hline & MP & 926 & -0.816 & -0.336 & 10228 & 2.06 & 0.001 & 66 \\
\hline & $\mathrm{SQ}$ & 283 & -0.451 & -0.096 & 8068 & 2.33 & 0.281 & 101 \\
\hline & $\mathrm{CB}$ & 407 & -0.724 & -0.744 & 11009 & 2.92 & 0.000 & 72 \\
\hline
\end{tabular}




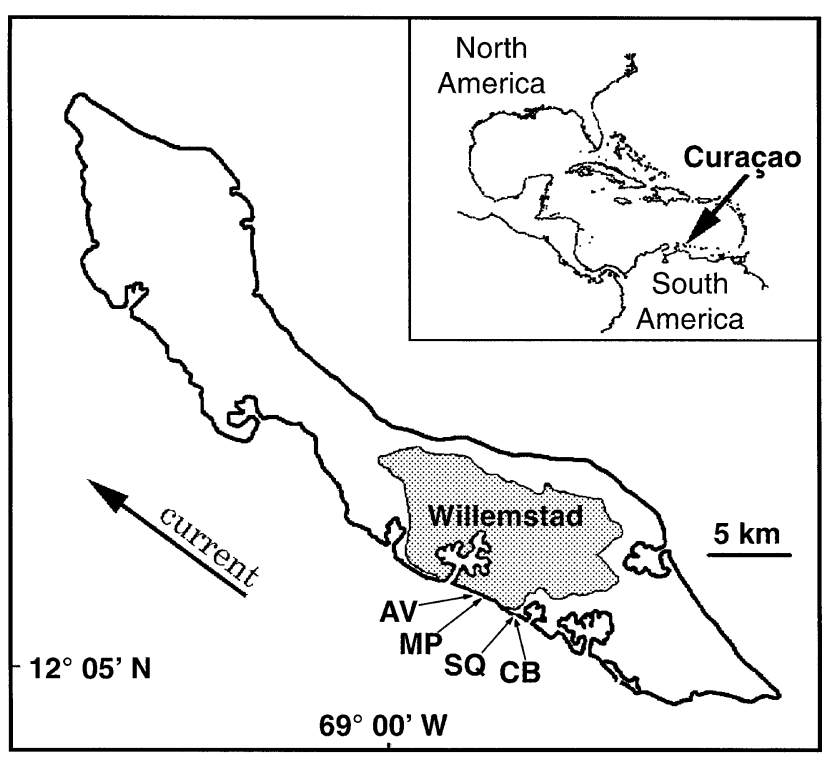

Fig. 1. Map showing locations of sampling sites on the southwest leeward coast of Curaçao, Netherlands Antilles. Shaded area: region with heavy urbanisation. AV: Avila; MP: Marie Pompoen; SQ: Seaquarium; CB: Cornelisbay

and at the middle of the maximum diameter, and the colony's geometric shape(s). Total surface area of each colony was estimated using the appropriate geometric formula(s) (e.g. spherical segment, cylinder and/or part spheroid). The surface area of Agaricia agaricites colonies was estimated by regression of total blade surface area per colony with measurements of length, width and height of the colony $\left(r^{2}=0.86\right.$, average deviation between observed and predicted area $0.3 \%$ ). The colony surface-area data were logarithmically transformed, and for each data series we calculated the frequency distribution parameters mean size, standard deviation, kurtosis, and skewness (Sokal \& Rohlf 1995).

Size-frequency distributions were compared to each other (2-sample Kolmogorov-Smirnov test) and to a normal distribution (single Kolmogorov-Smirnov test). Similarity between size-frequency distributions was calculated with the Spearman rank-correlation coefficient by dividing colony numbers into 12 size classes based on a logarithmic scale (class borders were $<0.37$, $1,2.7,7.4,20.1,54.6,148.4,403.4,1096,2980,8103$, and $>8103 \mathrm{~cm}^{2}$ ). Correlation coefficients were not normally distributed, and group means were tested with the Mann-Whitney $U$-test. Mean colony sizes were compared by ANOVA after log transformation of the data to reduce non-normality and heteroscedasticity. Where necessary, residuals were graphically examined to test assumptions of the analyses. For statistical analyses we used Systat 7.0 (SPSS Inc. 1997).

\section{RESULTS}

First, we will compare the general structure of coral size-frequency distributions, followed by a comparison of distribution parameters. In each comparison we will focus on variation between species and between sites.

\section{Size-frequency distributions}

Size-frequency distributions are given in Fig. 2. Logarithmically transforming colony-size data greatly improved normality. All distributions were more or less bell-shaped (Fig. 2) and 22 (42\%) of 52 distributions were statistically not significantly different from a normal distribution (Table 1, p > 0.05). Mean skewness of the distributions with logarithmically transformed data was -0.61 ( $\mathrm{SD}=0.46$ ), while distributions using nontransformed data were all significantly different from normality and highly skewed to the right (mean skewness $3.24, \mathrm{SD}=1.84$ ).

\section{Similarity between distributions}

We compared the general shape of the distributions by calculating the similarity between distributions (number of colonies in 12 logarithmically increasing size classes) using the Spearman rank-correlation coefficient. These comparisons showed that distributions of the same species (from different sites) were approximately twice as similar as distributions of different species. The mean correlation coefficient of intraspecific comparisons (distributions of the same species from different sites) was $0.80(\mathrm{SD}=0.14$, $\mathrm{n}=78$ ), while the mean correlation coefficient of comparisons between different species within the same site was 0.38 ( $\mathrm{SD}=0.45, \mathrm{n}=312$ ). These means of intraand interspecific comparisons are significantly different ( $p<0.0001$, Mann-Whitney $U$-test). The mean correlation coefficient of comparisons between distributions from different species at different sites was 0.37 ( $\mathrm{SD}=0.44, \mathrm{n}=1014)$, scarcely different from the mean interspecific correlation within the same site $(\mathrm{p}=0.519$, Mann-Whitney $U$-test). The relatively high degree of similarity between distributions from the same species (from different sites) suggests that population structure has characteristics unique to the relevant species.

Similarity of size-frequency distributions from the same species and differences between species were striking, but site differences were also marked (Fig. 2). Only in 2 species, Dichocoenia stokesiii and Montastrea cavernosa, did we find no significant difference between sites. In all other species there was at least 1 
Sites:
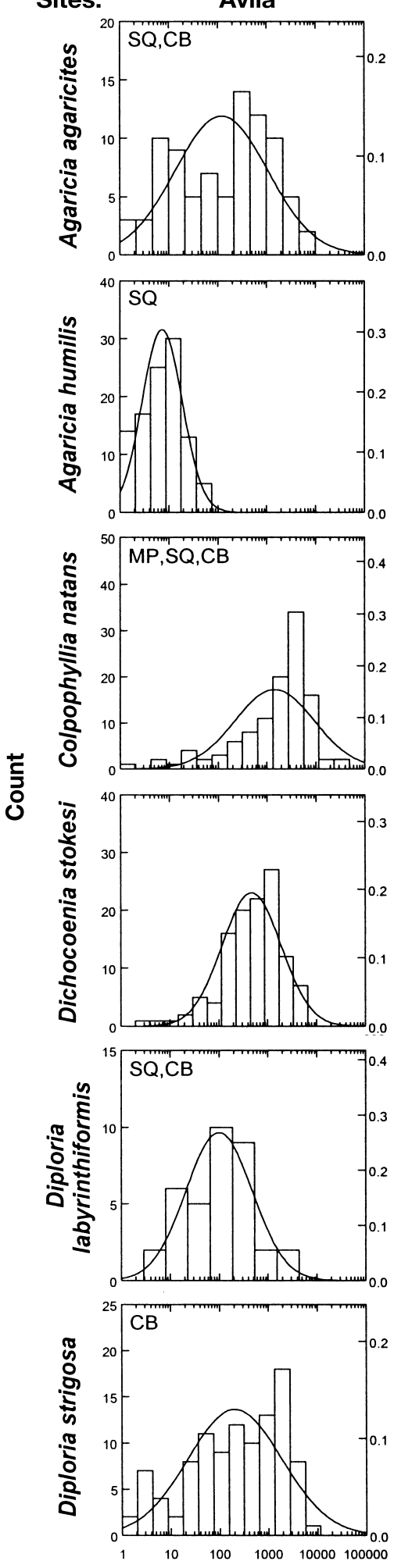

Marie Pompoen
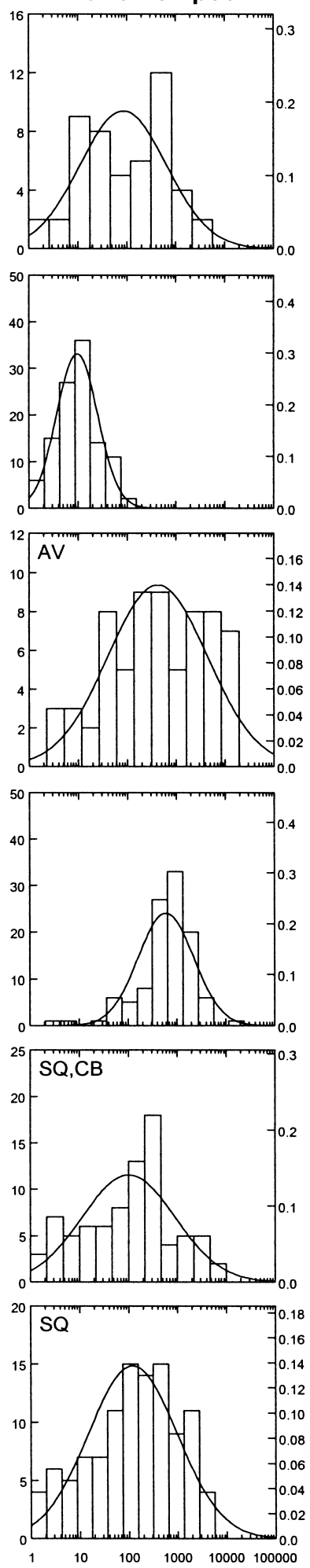
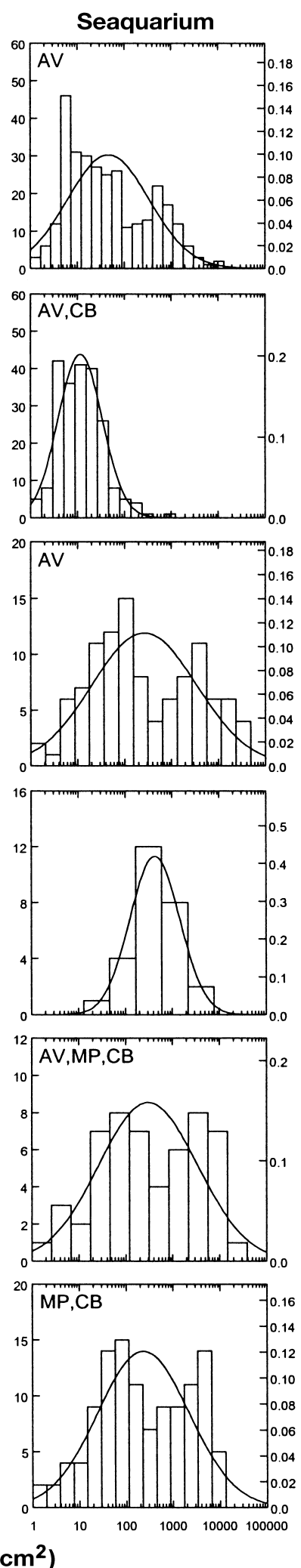
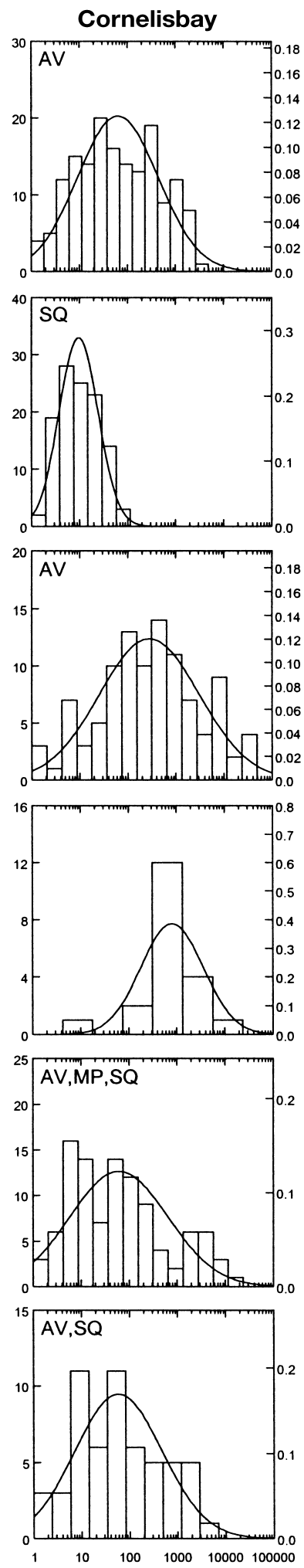

Size $\left(\mathrm{cm}^{2}\right)$

Fig. 2. Size (total surface area)-frequency distributions with overlaid normal distributions of measured colonies from 13 species and 4 sites. Note different scales on vertical axes. For each species, sites with significantly different distributions $(\mathrm{p}<0.05$, Kolmogorov-Smirnov test using Lilliefors correction) are indicated in top left corner of each graph. AV: Avila; MP: Marie Pompoen; SQ: Seaquarium; CB: Cornelisbay. Proportion per bar = proportion of sampled colonies of each species at each site 

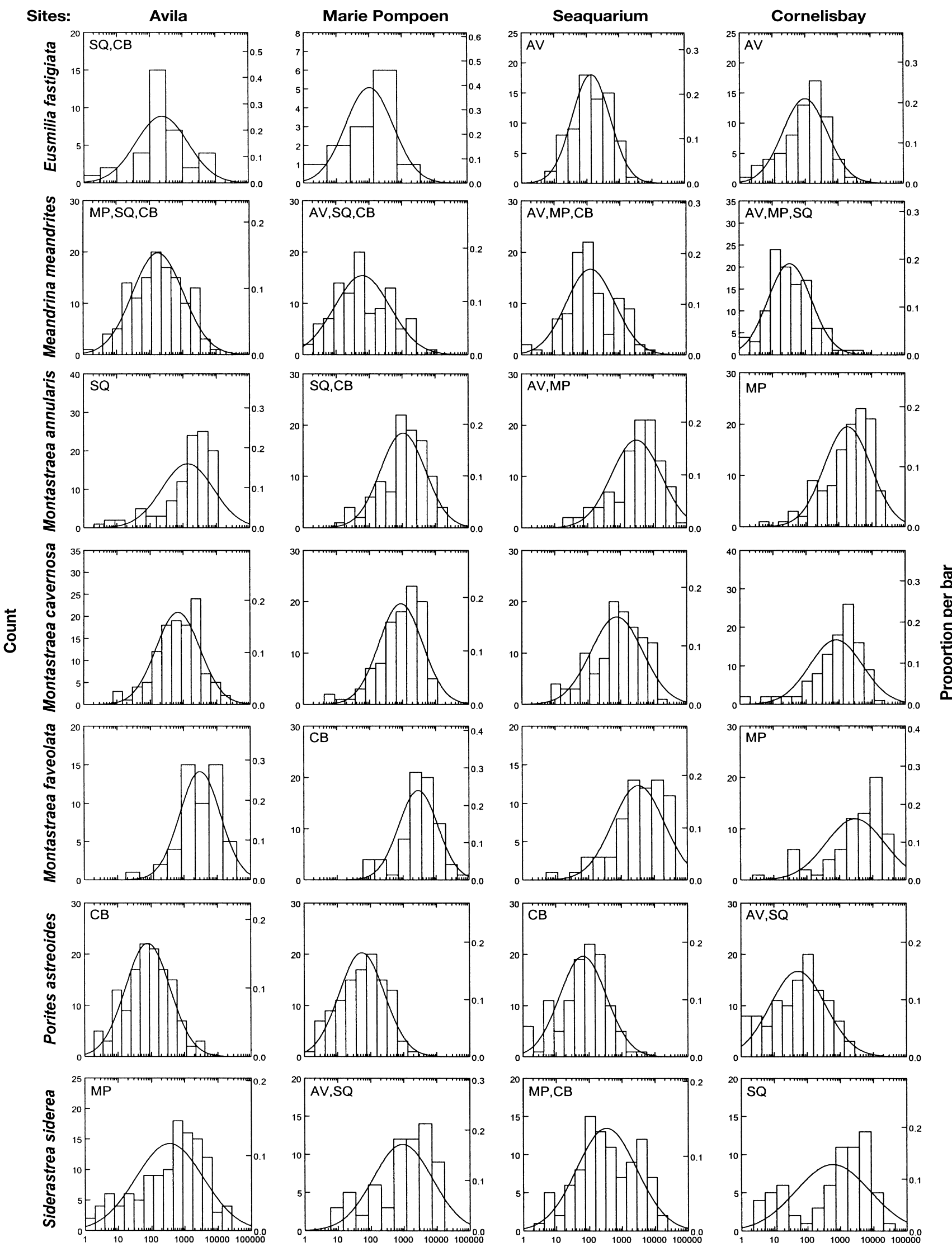

Size $\left(\mathrm{cm}^{2}\right)$

Fig. 2 (continued) 
pair of site comparisons that was significantly different (Fig. 2). Diploria labyrinthiformis and Meandrina meandrites appear to be very sensitive, having the highest number of significantly different distributions.

\section{Distribution parameters}

Table 1 gives the geometric mean size, skewness, kurtosis, maximum colony size, standard deviation, the probability that the sample is from a normal distribution, and sample size for specific coral populations at each site.

\section{Colony size}

Mean colony size varied greatly between species (Kruskal-Wallis 1-way ANOVA, test statistic 2183, $\mathrm{p}<0.000001, \mathrm{n}=5231$ ), and to a lesser degree between sites (Fig. 3, Table 1). Maximum colony size in a sample is very dependent on stochastic factors, and the 95th percentile provides an indication of the maximum colony size - a parameter that is more comparable among species (Soong 1993). Colony size often differed by an order of magnitude between species. For example, overall Agaricia humilis was the smallest species, with an average colony size of $<10 \mathrm{~cm}^{2}$, while Montastraea faveolata, the largest species, averaged around $3000 \mathrm{~cm}^{2}$. Ninety-fifth percentiles of these 2 species were 51 and $23510 \mathrm{~cm}^{2}$, respectively. The largest colony (95th percentile) was of Montastrea annularis and measured $33295 \mathrm{~cm}^{2}$.

Mean colony size indicated dichotomy in the response of species to the environment. Few species appear to be insensitive to the environment (Table 2); in only 3 of the 13 species did mean size not differ between sites: Dichocoenia stokesii, Montastraea cavernosa, and Montastraea faveolata (p 0.23, 0.91, 0.96, respectively). In all other species, differences between sites were highly significant. Highest significance was found for Colpophyllia natans, Meandrina meandrites, and Montastraea annularis. Fig. 3 shows a high variation in mean colony size within most species between sites. In some species, mean size varied as much as a factor of 5 (Table 1), e.g. Colpophyllia natans, $M$. meandrites and Diploria labyrinthiformis. There was also high variation in the 95th percentile value between sites.

When comparing a response variable of a group of species, we can expect either of 2 patterns: all species show the same pattern, or patterns of response differ. We found that species did not show the same patterns in colony size over the different sites (interaction species $\times$ sites, $F_{36,5179}=5.5, \mathrm{p}<0.00001 ; 2$-way ANOVA of size data). Whereas some species were smaller at certain locations (e.g. the sites near the urbanised area), other species showed the opposite pattern. General patterns over all species, such as smaller/larger colony size in degraded environments (sites Avila and Marie Pompoen), were absent, and no significant differences could be detected between the urbanised and control area.

\section{Standard deviation}

The standard deviations of the colony-size data differ significantly between species (ANOVA, $F_{12,26}=$ 20.7, p < 0.00001), even though logarithmic transfor-

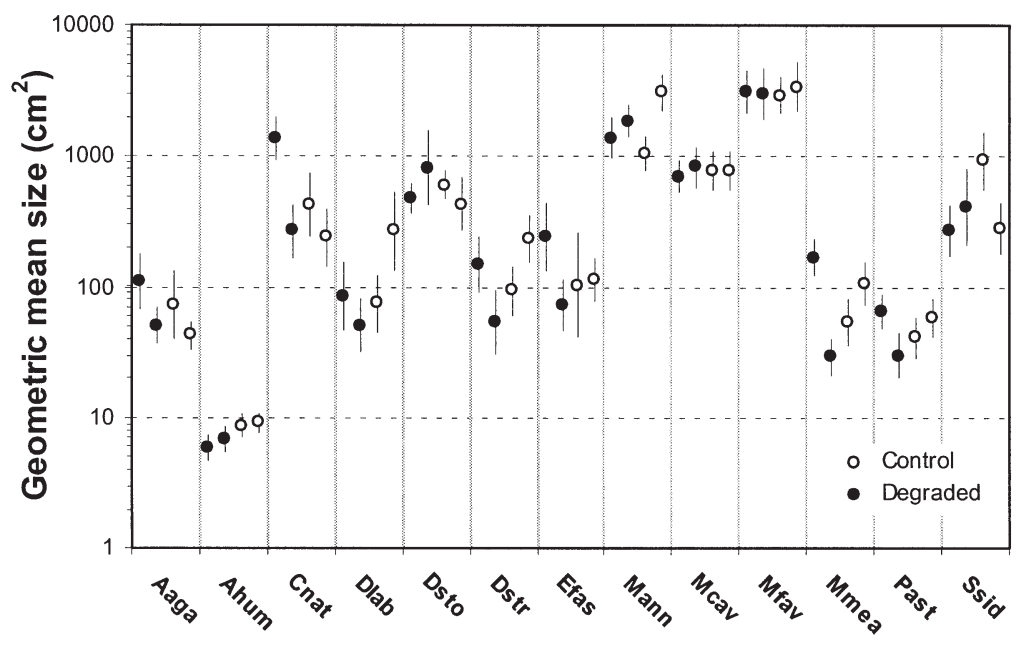

Fig. 3. Geometric mean colony size (and $95 \%$ confidence limits) at 4 sites for 13 coral species. Site order for each species: Avila, Marie Pompoen, Seaquarium, Cornelisbay. (•) Degraded sites, (०) control sites. Aaga: Agaricia agaricites; Ahum: A. humilis; Cnat: Colpophyllia natans; Dlab: Diploria labyrinthiformis; Dsto: Dichocoenia stokesii; Dstr: D. strigosa; Efas: Eusmilia fastigiata; Mann: Montastraea annularis; Mcav: M. cavernosa; Mfav: M. faveolata; Mmea: Meandrina meandrites; Past: Porites astreoides; Ssid: Siderastrea siderea 
mation of the data reduced the deviations to the same order of magnitude (Table 1). Comparison of areas and species in a variance components analysis (Sokal \& Rohlf 1995) revealed most variation (80\%) to be caused by differences between species. There was a small, but significant, difference in standard deviation between control and degraded areas (means $=1.33$ and $1.30, F_{1,12}=5.6, \mathrm{p}=0.025$, respectively), and in 9 species the standard deviation in the degraded area was smaller (Fig. 4). This suggests that colony size generally varies less in degraded areas. Variation between sites within each area (i.e. the error variation) accounted for $17.5 \%$ of the total variation.

\section{Skewness}

Skewness $\left(g_{1}\right.$ : Table 1$)$ is a parameter that describes the asymmetry around the mean of a frequency distribution. A distribution is said to be skewed to the left if its tail is drawn out to the left (i.e. the bulk of the distribution is on the right side); in such case, $g_{1}$ is negative. If the distribution is skewed to the right, the skewness parameter is positive. In a perfectly symmetrical distribution, $g_{1}$ is zero.

Most coral-size distributions were not symmetrical around the mean, but negatively skewed (48 out of 52 : Table 1). This indicates colony-size distributions withrelatively fewer colonies in the smaller size classes and a preponderance of larger colonies. Skewness varied significantly between species $\left(F_{12,26}=3.19, \mathrm{p}=0.006\right)$, reflecting specific rates of recruitment and mortality. There appeared to be a relationship between skewness and mean colony size (skewness $=-0.1698 \times$

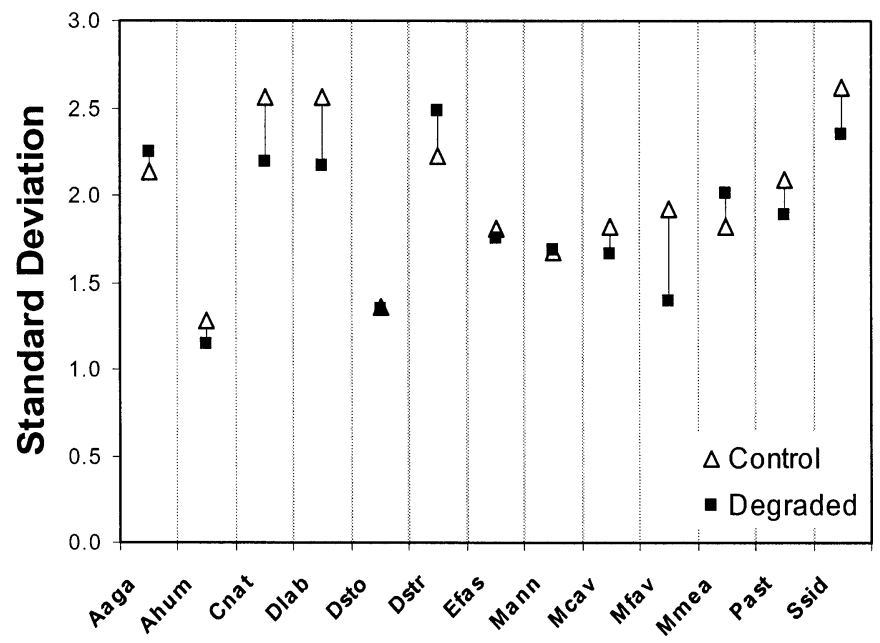

Fig. 4. Mean standard deviation based on logarithmically transformed colony size data from the 2 sites in each area (control and degraded). Species abbreviations as in Fig. 3
Table 2. Comparisons of mean colony size of species between 4 sites (1-way ANOVA). Data logarithmically transformed. $F$ : test statistic; p: probability of no difference between sites

\begin{tabular}{|lcrc|}
\hline Species & df & \multicolumn{1}{c|}{$F$} & $\mathrm{p}$ \\
\hline Agaricia agaricites & 3,619 & 4.84 & 0.00244 \\
Agaricia humilis & 3,597 & 4.21 & 0.00581 \\
Colpophyllia natans & 3,389 & 12.05 & 0.00000 \\
Dichocoenia stokesii & 3,270 & 1.45 & 0.22843 \\
Diploria labyrinthiformis & 3,282 & 5.67 & 0.00088 \\
Diploria strigosa & 3,392 & 5.84 & 0.00066 \\
Eusmilia fastigiata & 3,193 & 3.49 & 0.01676 \\
Meandrina meandrites & 3,451 & 19.03 & 0.00000 \\
Montastraea annularis & 3,421 & 7.50 & 0.00007 \\
Montastraea cavernosa & 3,441 & 0.18 & 0.90778 \\
Montastraea faveolata & 3,263 & 0.09 & 0.96454 \\
Porites astreoides & 3,498 & 4.12 & 0.00668 \\
Siderastrea siderea & 3,363 & 3.97 & 0.00832 \\
\hline
\end{tabular}

$\ln ($ size $\left.)+0.3082 ; \mathrm{r}^{2}=0.3863 ; \mathrm{p}<0.0001 ; \mathrm{n}=52\right)$, indicating that species with large mean sizes were more negatively skewed.

Species showed a similar response at the degraded sites $\left(F_{12,26}=1.15, p_{\text {species } \times \text { area }}=0.36\right)$. In the degraded area, size distributions were generally more skewed to the left (Fig. 5; $F_{1,26}=5.33, \mathrm{p}=0.03$ ), indicating relatively fewer smaller colonies and/or more larger colonies. Average skewness of all species combined was -0.71 for the disturbed area and -0.48 for the control area $(\mathrm{n}=26, \mathrm{SD}=0.069)$. Only Eusmillia fastigiata and Montastraea faveolata were less skewed in the degraded area. Differences between sites (within areas) accounted for $60 \%$ of the total variation in skewness (variance components analysis), while species, area, and the species-area interaction contributed 31,7 , and $2 \%$, respectively.

\section{Kurtosis}

Kurtosis $\left(\mathrm{g}_{2}\right)$ describes the peakedness of a distribution near its central mode. Population distributions can be leptokurtic $\left(g_{2}>0\right)$, i.e. very peaked/overcentralised, or platykurtic $\left(g_{2}<0\right)$, whereby the distribution is flatter than a normal distribution.

Kurtosis appears to be an extremely variable characteristic in coral populations. Of the 52 distributions in the data set, 24 displayed negative kurtosis and 28 were positive with no clear pattern (Table 1). In several species, there was extreme peakedness at at least 1 degraded site (Table 1; e.g. Colpophyllia natans, Diploria labyrinthiformis, Dichocoenia stokesii, Montastraea annularis, M. cavernosa). This variability in kurtosis was also expressed in the relative amount of variation as estimated by variance components analysis. Varia- 


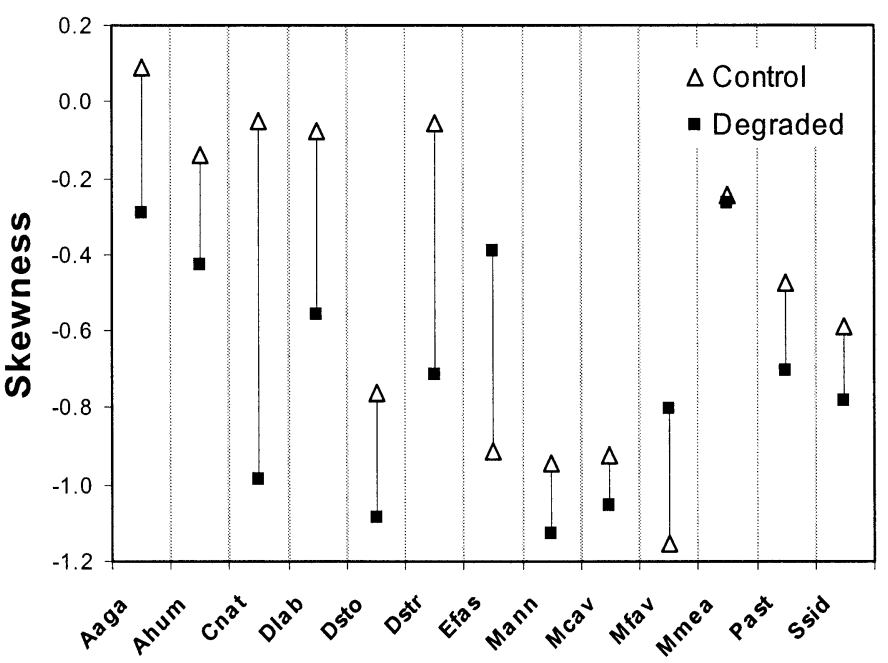

Fig. 5. Mean skewness based on logarithmically transformed colonysize data from the 2 sites in each area (control and degraded). Species abbreviations as in Fig. 3

tion between sites within each area was $82 \%$. Variation components of species and area were 13.5 and $4.5 \%$, respectively. No significant differences existed between species $(p=0.12)$ or between areas $(p=0.10)$. However, probability values were close to significance and worth exploring further. Average kurtosis was 0.08 and 0.56 for control and degraded areas, respectively, indicating a large difference. Extremes in kurtosis were mostly in the degraded area (Table 1). Average kurtosis was highest at Avila, followed by Marie Pompoen, Seaquarium, and Cornelisbay (Fig. 6). Available data suggest that this order is also valid for the general environmental quality of the reefs at these sites (van Duyl 1985, Gast et al. 1999).

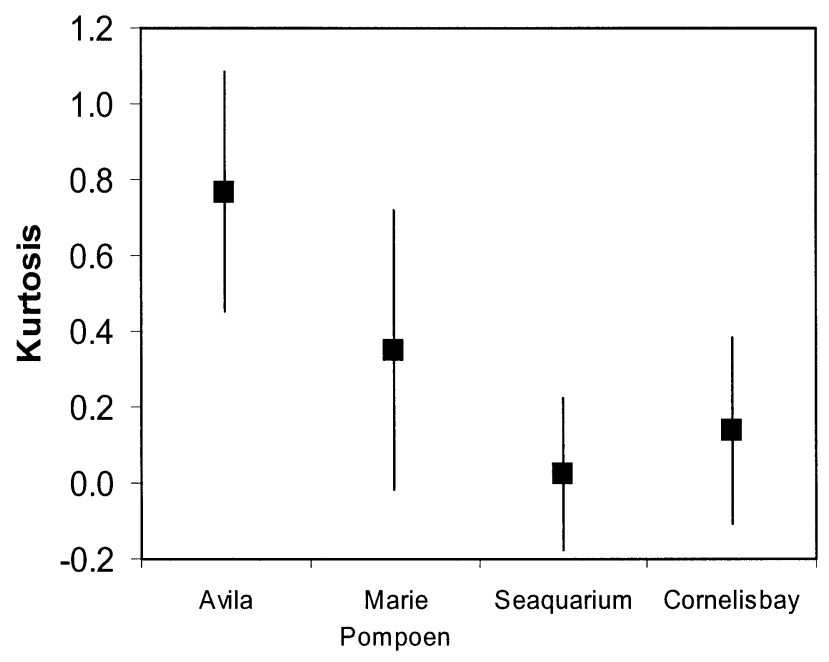

Fig. 6. Kurtosis. Average $( \pm \mathrm{SE})$ of 13 coral species at 4 sampling locations

\section{DISCUSSION}

This study has shown that coral populations vary enormously in structure and that these differences can be detected through estimating statistical parameters of frequency distributions. Differences between populations appeared to be related to environmental degradation. In an area bordering a heavily urbanised coastal region, size-frequency distributions of populations of many species were found to: (1) have relatively few colonies in the smaller size classes and more larger colonies (increased negative skewness), (2) have lower standard deviation, and (3) be often more centralised (i.e. increased kurtosis). These distributions are the outcome of changes in life-history processes such as growth, partial colony mortality, and recruitment. Such changes may be difficult to detect when each process is assessed by itself because of high variation between colonies. But if the whole population is assessed, the combined effects of these processes may become conspicuous through shifts in population structure.

Remarkable in our results is the high similarity (0.80) between distributions from the same species (over 4 sites), indicating that population structure is highly species-specific. This similarity is partly due to the mean colony size which determined the central location of the distribution on the abscissa of Fig. 2 and differed greatly between species (Fig. 4). Further evidence for the importance of species-specific effects on life-history processes is the relative importance of species as a source of variation in the several variance components analyses. Mean colony size and 95th percentile size appear to be very variable, mostly between but also within species. This suggests that within the genetic constraints of each species, colony size is to a large extent influenced by the environment.

Interspecific differences in colony size are so large that the question arises whether coral colony growth is really indeterminate (indeterminate growth Type II/III sensu Sebens 1987). For example, size differences between Agaricia humilis and Montastraea faveolata (Fig. 4, Table 1) are so great that it appears highly unlikely that $A$. humilis has the genetic potential to reach the same size as $M$. faveolata. The same argument is valid for comparisons between other species. The amount of genetic versus environmental control of colony size is likely to differ between species and is difficult to establish. As already indicated by Sebens (1987), the term 'indeterminate growth' is confusing, and the terms (genetically) 'constrained' versus 'plastic' growth are more suitable. Coral colonies can shrink in size through partial mortality and, although much 
less frequently (Bythell et al. 1993), increase in size by fusion. Disappearance from the population through whole-colony mortality is rare, and colonies shift into larger as well as smaller size classes, complicating explanation of observed patterns. However, despite these problems in interpretation, size-frequency distributions often provide the only easily available clues to the underlying dynamics of growth, survival, and recruitment, since long-term data are lacking for most coral communities. Through early shifts in population structure we may be able to discern species that respond quickly to environmental perturbation. For example, Colpophyllia natans and Diploria labyrinthiformis showed strong responses in mean colony size, skewness, kurtosis, and SD in the degraded area, mainly at Avila (Fig. 2, Table 1).

At least as interesting as size-distribution differences between sites is the fact that some species did not show differences in mean size and/or size distribution. Such species appear to be insensitive to the range of environmental conditions of the 4 sites or have strategies that stabilise population structure. Species that did not show a significant difference between distributions at the 4 sampling sites were Dichocoenia stokesii and Montastraea cavernosa (Fig. 2). Mean colony size also did not differ between sites in these species (Table 2). In contrast to such inflexibility is the fact that both species show enhanced negative skewness in the degraded area (Fig. 5). Thus, skewness appears to be a more sensitive indicator of change in such coral populations.

We found that in many cases the site considered most heavily degraded, namely Avila, had the largest mean colony size (Fig. 3). Measuring colony size or coral cover, interpreting larger measurement as positive signals, can obscure a decline in reef quality. Mean size can stay the same or even increase, because populations shift toward dominance by older (larger) individuals. Small colonies do not contribute much to total coral cover. Skewness of size distributions has rarely been used to assess coral populations (but see Bak \& Meesters 1998, 1999), whereas in plant ecology it is widely used as a measure of inequality among members of populations (e.g. Hara 1988, Bendel et al. 1989, Santos 1995). Most plant populations consist of many small individuals and relatively few large ones that comprise most of the population's biomass and thus contribute inordinately to the gene pool of the next generation. This situation is similar in coral populations (Hughes et al. 1992). In our study, the largest $5 \%$ of the sampled populations represented $33.2 \%$ $(\mathrm{SD}=10.5, \mathrm{n}=52$ ) of the total colony surface area. Populations with the aforementioned characteristics are often designated 'size hierarchies' (Weiner 1985). The ecological and evolutionary significance of these pop- ulation characteristics is great. The evaluation of size hierarchies has led to some confusion (Weiner 1985), and different measures of size inequality are used (Bendel et al. 1989). Skewness has been used to determine the onset of self-thinning due to differential growth rates between larger and smaller 'suppressed' plants (Weiner \& Thomas 1986), confirming the asymmetric competition hypothesis of dominance and suppression of smaller individuals by larger ones (Begon 1984).

The population structure of coral species has been little studied in the field, presumably because of the extreme requirements of underwater survey efforts to collect colony-size data. It has been addressed mostly in demographic studies that include modelling of population growth (Hughes \& Jackson 1985, Fong \& Glynn 1998). These studies have not analysed the results in statistical terms such as those used here, but general conclusions may be drawn from the shape of the distribution of the populations under several conditions. Fong \& Glynn (1998), for example, showed how predation by Acanthaster planci may skew populations of the coral Gardineroseris planulata towards a larger proportion of smaller colonies. In contrast, Bak \& Meesters (1999) and the present study imply that environmental deterioration will skew populations in the opposite direction. A possible explanation may be that A. planci effectively forages in a 'line transect', and consequently smaller colonies have less chance of being encountered and attacked; larger colonies are relatively more affected, so populations under predation pressure tend to develop a surplus of smaller colonies. Thus, different factors produce different population size distributions, depending on when and where they affect the population.

Soong (1993) analysed populations of Caribbean corals (Panama) from similar depths using a linear scale for his size classes, and found populations to be highly skewed to the right. Interesting, and directly comparable with our data, is this 95th percentile of colony size. For Porites astreoides, Siderastrea siderea, Montastrea cavernosa, and Diploria strigosa, Soong found 180, 3094, 5369, and $7176 \mathrm{~cm}^{2}$, respectively, compared to our values of $728,9040,7304$, and $3363 \mathrm{~cm}^{2}$ (mean 95th percentile of 4 sites). These differences seem too large to be explained solely by a different method of measuring colony size (Soong 1993 used maximum width times maximum length, whereas we measured length, width, height and approximated the colony to a geometrical shape). If we calculate surface area using Soong's formula, we find 302, 4080, 2466, $1695 \mathrm{~cm}^{2}$, respectively, for the 95th percentiles. This shows primarily that ignoring height in calculating colony surface area has tremendous influence on surface-area estimations. Furthermore, this effect is spe- 
cies-dependent and basically the consequence of the general morphology of the species concerned (and, as such, also influenced by water depth). Nevertheless, a comparison of surface areas calculated as in Soong (1993) shows differences between species. In Curaçao colonies of $P$. astreoides and $S$. siderea are larger, whereas $M$. cavernosa and $D$. strigosa are smaller than in Panama. Possibly this is an effect of the environment on life-history processes that structure the populations. On the other hand, a comparison between Curaçao and Panama involves distant portions of these species' metapopulations, and differences in the potential size ranges of these species may be genetically determined.

In almost all studies that deal with population structure, colony-size classification is linear and distributions are very skewed to the right (Hughes \& Jackson 1980, 1985, Babcock 1984, Bythell et al. 1993, Soong 1993, Lewis 1997). Most life-history variables in coral ecology, however, vary exponentially with colony size (e.g. Hughes et al. 1992). Bak \& Meesters (1998) suggested that using a logarithmic scale to construct sizefrequency distributions might be more appropriate for the study of populations. Koch (1966) showed how lognormal distributions may arise in biology in several ways. If exponential growth rates are normally distributed and new recruits are of equal size or normally distributed, the size distribution of plants after a period of growth will be log-normal. Theoretically, early surface growth in new recruits of modular organisms is exponential (Hughes 1989), but intrinsic and/or extrinsic factors may cause deviations from exponential growth. Coral colonies often have sigmoid growth curves (Loya 1976a), indicating that early growth is exponential. Since the patterns of relative abundance, the size-frequency distributions, arise from the interplay of many independent factors, distributions are likely to be lognormal (May 1975). Furthermore, although size and age are not directly related in corals (Hughes \& Jackson 1980), they should be strongly correlated if partial mortality is low, such as for example in small corals (Meesters et al. 1996, 1997). Using a multiplicative scale would under such conditions approximate an age distribution. Consequently, age distributions should be generally less skewed than (linear) size distributions. Babcock (1991) gives size- and age-frequency distributions, and his results show skewness to be clearly lower in the latter.

Present-day environmental threats to coral reefs include the effects, and possibly synergistic interaction, of chemical pollution, increased sediment load, increased seawater temperatures, and diseases. Monitoring of corals over time while concurrently monitoring various environmental parameters will provide considerable insight into the effects of environmental factors on causal life-history processes. If sufficient information is available on specific effects on lifehistory processes, predictions can be made as to the long-term development of populations. Our results would suggest that the influx of small colonies is limited in degraded areas, that partial mortality is important in limiting size in populations, but that these are species-specific phenomena. In some species, extreme peakedness suggests the synergistic effect of both processes in degraded reefs.

In conclusion, we showed that colony-size distributions of scleractinian corals have characteristics that are species- and site-specific. All species tend to have log-normal distributions, and most species distributions vary in different environments. The data suggest that distribution of healthy populations is almost log-normal, with moderate (usually slightly negative) values of $g_{1}$ (skewness). In degraded environments, the number of small colonies appears to decrease (increased negative skewness), distributions often become centralised (high positive kurtosis), and standard deviations of colony size tend to decrease. The question raised, and to be tested in other environments, is: can we infer from specific deviations from normality that a population is (becoming) less healthy? Populations will continuously shift between certain boundaries in response to variation in recruitment, growth, and survival. The extent to which this variation is reflected in size distributions should be studied, possibly over time, in more pristine and in more marginal reef environments.

Acknowledgements. We thank the staff of Carmabi Institute for providing facilities and logistic support. We would like to thank 4 anonymous reviewers for their helpful comments. The research was supported by the Society for the Advancement of Research in the Tropics (Treub-fonds), Netherlands Foundation for the Advancement of Tropical Research (WOTRO), and the Royal Dutch Academy of Science (KNAW). This is NIOZ publication number 3425 .

\section{LITERATURE CITED}

Aronson RB, Precht WF (1997) Stasis, biological disturbance, and community structure of a holocene coral reef. Paleobiology 23:326-346

Babcock RC (1984) Reproduction and distribution of two species of Goniastrea (Scleractinia) from the Great Barrier Reef Province. Coral Reefs 2:187-195

Babcock RC (1991) Comparative demography of three species of scleractinian corals using age- and size-dependent classifications. Ecol Monogr 61:225-244

Bak RPM (1975) Ecological aspects of the distribution of reef corals in the Netherlands Antilles. Contr Zool 45:181-190

Bak RPM (1976) The growth of coral colonies and the importance of crustose coralline algae and burrowing sponges in relation with carbonate accumulation. Neth J Sea Res 10:285-337 
Bak RPM, Meesters EH (1997) Coral diversity, populations and ecosystem functioning. In: Den Hartog JC (ed) Proceedings 6th International Conference Coelentarate Biology. National Museum Natural History, Leiden, p 27-38

Bak RPM, Meesters EH (1998) Coral population structure: the hidden information of colony size-frequency distributions. Mar Ecol Prog Ser 162:301-306

Bak RPM, Meesters EH (1999) Population structure as a response of coral communities to global change. Am Zool 39:56-65

Bak RPM, Nieuwland G (1995) Long-term change in coral communities along depth gradients over leeward reefs in the Netherlands Antilles. Bull Mar Sci 56:609-619

Begon M (1984) Density and individual fitness: asymmetric competition. In Shorrocks B (ed) Evolutionary ecology. Blackwell, Oxford, p 175-194

Bendel RB, Higgins SS, Teberg JE, Pyke DA (1989) Comparison of skewness coefficient, coefficient of variation, and Gini coefficient as inequalitiy measures within populations. Oecologia 78:394-400

Birkeland C (1996) Life and death of coral reefs, Chapman \& Hall, New York

Buddemeier RW (1993) Corals, climate and conservation. Proc 7th Int Coral Reef Symp 1:3-10

Bythell JC, Gladfelter EH, Bythell M (1993) Chronic and catastrophic natural mortality of three common Caribbean reef corals. Coral Reefs 12:143-152

Connell JH (1973) Population ecology of reef-building corals. In: Jones OA, Endean R (eds) Biology and geology of coral reefs. Academic Press, London, p 271-324

Ebert TA, Schroeter SC, Dixon JD (1993) Inferring demographic processes from size-frequency distributions: effect of pulsed recruitment on simple models. Fish Bull US 91:237-243

Fong P, Glynn PW (1998) A dynamic size-structured population model: does disturbance control size structure of a population of the massive coral Gardineroseris planulata in the Eastern Pacific? Mar Biol 130:663-674

Gast GJ, Jonkers PJ, Duyl FCv, Bak RPM (1999) Bacteria, flagellates and nutrients in the coral reef waters along the coast of Curaçao, Caribbean Sea in relation to eutrophication. Bull Mar Sci 65:523-538

Ginsburg RN, Glynn PW (1994) Summary of the colloquium and forum on global aspects of coral reefs: health, hazards and history. RSMAS, University of Miami, Miami, p I-IX

Gosselin LA, Qian P (1997) Juvenile mortality in benthic marine invertebrates. Mar Ecol Prog Ser 146:265-282

Hara T (1988) Dynamics of size structure in plant populations. Trends Ecol Evol 3:129-133

Highsmith RC, Riggs AC, D'Antonio CM (1980) Survival of hurricane-generated coral fragments and a disturbance model of reef calcification/growth rates. Oecologia 46: 322-329

Hughes RN (1989) A functional biology of clonal animals. Chapman and Hall, New York

Hughes TP, Connell JH (1987) Population dynamics based on size or age? A reef coral analysis. Am Nat 129:818-829

Hughes TP, Jackson JBC (1980) Do corals lie about their age?

Editorial responsibility: Otto Kinne (Editor),

Oldendorf/Luhe, Germany
Some demographic consequences of partial mortality, fission and fusion. Science 209:713-714

Hughes TP, Jackson JBC (1985) Population dynamics and life histories of foliaceous corals. Ecol Monogr 55:141-166

Hughes TP, Ayre D, Connell JH (1992) The evolutionary ecology of corals. Trends Ecol Evol 7:292-295

Koch AL (1966) The logarithm in biology. 1. Mechanisms generating the log-normal distribution exactly. J Theor Biol 12:276-290

Leslie PH (1945) On the use of matrices in certain population mathematics. Biometrika 33:213-245

Lewis JB (1997) Abundance, distribution and partial mortality of the massive coral Siderastrea siderea on degrading coral reefs at Barbados, West Indies. Mar Pollut Bull 34: $622-627$

Loya Y (1976a) The Red Sea coral Stylophora pistillata is an r-strategist. Nature 259:478-480

Loya Y (1976b) Skeletal regeneration in a Red Sea scleractinian coral population. Nature 261:490-491

May RM (1975) Patterns of species abundance and diversity. In: Cody ML, Diamond JM (eds) Ecology and evolution of communities. The Belknap Press of Harvard University Press, Cambridge, MA, p 81-120

Meesters EH, Wesseling I, Bak RPM (1996) Partial mortality in three species of reef-building corals (Scleractinia) and the relation with colony morphology. Bull Mar Sci 58:838-852

Meesters EH, Wesseling I, Bak RPM (1997) Coral colony tissue damage in six species of reef-building corals: partial mortality in relation with depth and surface area. J Sea Res 37:131-144

Santos R (1995) Size structure and inequality in a commercial stand of the seaweed Gelidium sesquipedale. Mar Ecol Prog Ser 119:253-263

Sebens KP (1987) The ecology of indeterminate growth in animals. Annu Rev Ecol Syst 181:371-407

Sokal RR, Rohlf FJ (1995) Biometry. The principles and practice of statistics in biological research, 3rd edn. WH Freeman \& Company, New York

Soong K (1993) Colony size as a species character in massive reef corals. Coral Reefs 12:77-83

SPSS Inc (1997) Systat 7.0 for Windows. Chicago

Szmant A (1991) Sexual reproduction by the Caribbean reef corals Montastrea annularis and M. cavernosa. Mar Ecol Prog Ser 74:13-25

Underwood AJ (1997) Experiments in ecology, Cambridge University Press, Cambridge

van Duyl FC (1985) Atlas of the living reefs of Curaçao and Bonaire (Netherlands Antilles). Foundation for Scientific Research in Surinam and the Netherlands Antilles, Utrecht, $117: 1-37$

Weiner J (1985) Size hierarchies in experimental populations of annual plants. Ecology 66:743-752

Weiner J, Thomas SC (1986) Size variability and competition in plant monocultures. Oikos 47:211-222

Wilkinson CR (1993) Coral reefs of the world are facing widespread devastation: can we prevent this through sustainable management practices? Proc 7th Int Coral Reef Symp $1: 11-21$

Submitted: November 2, 1999; Accepted: May 18, 2000

Proofs received from author(s): November 27, 2000 